\title{
Comprehensive bim system for control of construction production and resource support
}

\author{
Nikita Shcherba* and Marat Kuzhin \\ Moscow State University of Civil Engineering, Moscow, Russia, 129337
}

\begin{abstract}
Subject of research is analysis of the possibilities for the development of integrated management systems for construction production using BIM technologies in the field of resource provision of the construction site. Objectives: study the features and problems of the modern approach to control over the distribution of material resources and construction management in terms of the implementation of design solutions. Research into the implementation and use of information technologies to improve the organization of construction production at the construction site of an industrial facility, preparation for construction at the design stages and before design. Results: the obsolescence of the classical approaches and methods of construction control and the effectiveness of the use of complex programs that combine all the tools for effective construction management have been proved. The main directions in the field of improving the tools for monitoring the resource provision of construction are identified. A methodology for organizing a calendar schedule and monitoring the sufficiency of materials and resources through the concept of " assignment" for a construction contractor is proposed . Conclusions: using of integrated computer systems already in 2020 allows for effective construction control, especially in matters of accurate, correct and timely provision of the construction site with the necessary materials. An important conclusion that was obtained as a result of the research is that the creation of a unified software system for the control system for construction production is a priority task in the field of organizing construction production. Simplicity, comfort of use even in the most remote areas of construction makes such systems indispensable and greatly facilitate the work of construction management.
\end{abstract}

\section{Introduction}

Today, in 2020, digital technologies will surprise no one. In almost every area of our life, the digital organization of the process has come to the fore. Undoubtedly, these trends have not spared construction.

The construction industry is a huge field for investments, innovations and innovations. The use of BIM only at the design stage does not reveal the full potential of the benefits of this technology. BIM unleashes its potential at the construction stage, both in

\footnotetext{
*Corresponding author: n1 ckito@inbox.ru
} 
the field of early planning of construction and installation works, the scheduling and linking it with the equipment delivery schedules, and in terms of material and technical resources necessary for a normal, rhythmic construction process.

Every person who is somehow connected directly with the construction site has to face many problems that arise due to lack of control, monitoring of the construction process, resource use, tracking the already built parts of buildings and structures and understanding how much and what materials are needed to complete construction. Digitalization, communication with a unified model of a building or structure, control and monitoring of construction processes and expenditure of material and technical support is the most important task of ensuring the fast, economical and low-cost construction of any facilities, including industrial production facilities.

It is important to immediately indicate that BIM in the current stage of development is already used not only at the design stage of an object, but also at all stages of an investment project. Ginzburg A.V. in his work indicates that the life cycle of an object covers all the time from the first concept to the disposal of construction waste [1]. This statement reveals the potential for using BIM technologies in construction, since the information component is present at all stages of an investment construction project. It is important to understand that every year the array of information is growing and a person, without the use of special technologies, does not have enough mental resources to process it. This is especially important from the point of view of ensuring control at the construction site, without the use of modern tools, the customer cannot efficiently and timely assess the progress of construction production [2]. Especially difficulties arise in cases when the construction site is located at a great distance from the customer's services, which happens very often during the construction of industrial facilities, since the objects of the oil and gas sector are often tied to fields.

At the construction stage, time is one of the most important indicators characterizing the success and economy of the construction of an object. Only taking into account the time frame, the customer can track the readiness of the object for any specific period of time, and also be able to optimize the construction process in one way or another, so as not to disrupt the planned deadlines. The timetable is closely related to the building information model [3]. In other words, a classic timetable that does not account for real-time changes in the building model is not suitable for full-scale construction control.

In fact, we are talking about the 4th dimension of the information model. Ermolov D.E. in his work indicates that such well-known systems as Microsoft Project, Oracle Primavera and other similar software products do not provide a visual and complex representation of the ongoing processes, as can be done using a 3D BIM model of an object [4]. The above software products can only work in conjunction with such programs as Autodesk Navisworks, Bentley Navigator, Visual5D [5]. An example of the relationship between Navisworks and simple programs such as MS Excel is described in the work of A.M. Eleishikha. [6]. The author, using macros, converts a calendar chart from Excel to Navisworks for interconnection with the 3D object model. However, this system is cumbersome and inflexible; there is no interconnection with other important sections of the construction process, for example, the connection between the schedule and the material and resource support of construction.

Undoubtedly, effective management of construction production requires not just a calendar schedule, but the most detailed schedule [7]. Losses in time and economic indicators often depend on "little things" that cannot be tracked when applying the enlarged schedule.

At present, the most acute problem is the problem of automating the processes of control of the work schedule, distribution of material resources, accounting for the volume of completed and forthcoming work, control of document flow at the construction site [8, 
9]. The problem is that at the moment there are practically no ready-made domestic integrated systems for solving these problems.

The author emphasizes that the combination of classical project management with a $3 \mathrm{D}$ model gives a significant increase in efficiency. The formation of a 4D model improves the relationship between all participants in an investment project during construction, and most importantly, it makes it possible to find space-time collisions during construction work [4]. For these purposes, it is proposed to use the Synchro system, as the most complex and time-tested solution. This system is actively used even at hazardous industrial facilities, for example, atomic ones [10]. The disadvantage of this program is that it is a foreign development, i.e. rather expensive and cannot fully take into account the peculiarities of construction management and management in our country.

Another example of the use of a 4D system in the interaction of a $3 \mathrm{D}$ model and a construction schedule is the software product from GENPRO [11]. The already described bundle of programs is used: Navisworks and MS Project. Another example is the use of MS Excel to calculate the volume of work and MS Project to build a calendar [12]. Software products are effectively used to build a 4D simulation model of an object, but the connection between the calendar schedule and the delivery schedule for building materials, logistics, and material and technical support of construction production is poorly traced. In fact, these software solutions solve a certain range of problems, but are not complex solutions, since many middleware are used.

The combination of Primavera and Archicad has gained widespread use in attempts to use BIM technologies in construction management processes [13]. This system seems to be quite effective, since the authors describe a multi-level breakdown of the construction schedule, which includes information on the amount of work, labor costs and the necessary material and technical resources. However, the above-described system is not an integrated system for the design and management of construction production, as it is intended for narrow purposes of tracking the schedule without solving the problems of delivery of materials, their control over their placement and use, and many other tasks.

The work carried out in the field of 4D design, using such programs as: MS Project + Turbo Planner, Primavera, Adept, Spider Project, shows that at the moment there are few domestic complexes that can solve the problems of organizational and technological design in conjunction with construction management. We repeat that another significant drawback of these foreign combinations of programs is the high cost of software, which repels potential users outside of Russia [14]. As a result of this analysis, the authors of the article indicate that work is underway to develop their own domestic software, which will make it possible to link the schedule and the construction plan, the relationship between estimated calculations and the BIM model, and assess the effectiveness of construction even at the investment stage.

It is not a secret for anyone that the logically correct distribution of material resources from the stage of project conception to the purchase of materials, as well as tracking the delivery of materials, is one of the key tasks of logistics to ensure successful management of project implementation $[15,16]$. Logistic errors are difficult to track down, but in the long term they are of decisive importance in solving the problems of control of the construction production schedule, especially considering that the construction site is often unique and competent planning is required to ensure the delivery of the necessary materials. It is for this reason that in our time it is necessary to develop and improve software that can help in solving these problems [17].

At the present stage of development of BIM technologies, the next stage of "depth and detail" of the model is developing - the so-called 5th space, i.e. in addition to the time factor of project evaluation, one of the most important for the investor is added - the cost factor. This factor is one of the most important, since the cost of the object is the main 
factor in attracting investment funds for the project. Consequently, it is the investor who is interested in a clear and transparent tracking of not a static, but a dynamically changing system of object value. The binding of prices to specific elements of the model reduces to almost zero the likelihood of force majeure costs [18].

It is important to note that the material specifications required for calculating the actual construction prices of objects should be dynamically changeable, i.e. the use of BIM models is mandatory in conjunction with the formation of estimates [19]. The model is actually the basis for the formation of estimates and makes it possible, for example, to accurately calculate the required amount of concrete and reinforcement in order to understand the cost of these resources [20].

TrioBoxWIZARD software [19], as well as a set of INFARS Group based on Autodesk Navisworks [21], solve the problems of linking estimates to the BIM model of an object using a classifier of model elements, but they are not a comprehensive solution in terms of other construction management tasks, which makes this process is cumbersome, expensive and depends on many software systems.

It is obvious that the solution of these problems is more and more urgent, since in the future, control and automation of estimate calculations may become mandatory at project facilities that are financed by the budget of the Russian Federation [19].

5D modeling and design is a modern, rapidly developing technology that provides an opportunity to attract an investor, and gives him a tool for comprehensive control over the distribution of invested funds. At least that's what all BIM companies strive for. However, in our time, the logical continuation of the development of BIM technologies receives the following dimension - 6D.

$6 \mathrm{D}$ technologies in construction is an actual (executive) model that can be used in the process of unfinished construction, as well as in the future, at the stage of object operation. As part of the topic of the final work, we will focus only on the 1 st option for using 6D technology.

The executive model of the object can be used for organizing and planning construction and installation work, including in matters of equipment and availability of the necessary material and technical resources, as well as for designer supervision of construction production [22]. The rhythm and efficiency of construction and installation work, compliance with the previously developed construction schedule - can be easily controlled using actual BIM models of the facility. Understanding the situation at the construction site allows you to make timely management decisions [23,24]. Consequently, the FACT model is an integral part of controlling the consumption of material and technical resources at the construction site.

It can be concluded that the problems of improving control over the resource provision of the construction site of the facility require further studies and innovations. Despite a considerable number of programs and complexes designed to help in the control and management of construction in this period of time, there are no comprehensive solutions that can solve these problems in conjunction with other aspects of the construction management. Some solutions are seen as cumbersome and inflexible, which to a large extent stops potential investors and customers who are ready to introduce these innovations on their construction sites.

\section{Materials and methods}

In the process of writing this scientific article, scientific and research works of well-known domestic and foreign specialists were used, the experience of building large Russian industrial facilities was analyzed. The main research method in the article is analytical research, analysis and synthesis. 


\section{Results}

Effective management of construction production is possible only if the following parameters are simultaneously monitored and linked:

- the budget of construction - analysis and monitoring of the cost of a construction object;

- construction time - control of the construction and installation work schedule within the time frame and the correct sequence;

- monitoring the contractor - issuing specific assignments to the contractor indicating the necessary materials to ensure its implementation, monitoring the implementation of the assigned assignment.

- logistics of providing resources - timely provision of the construction site with materials and resources.

The scientific article discusses the methods to ensure effective control of the above parameters in a convenient and quick form.

Currently, in the Russian Federation there are very few software systems capable of ensuring the control of the above parameters in a single environment using the BIM model of the object. At the moment, a lot of programs have been created that can effectively solve individual important tasks of managing construction production. However, small enough whole software systems that can combine the results of the use of a variety of other tools in a single location on a single platform, ensuring easy and quick access even to remote construction sites, but still at an affordable price of the software package and its maintenance.

One of the complexes that offers its own approaches to forming a digital environment for construction management is the Assistant Build software package .

This software is the resultant platform capable to link information model (model of programs such as Revit, Tekla, Advanced Steel, Plant 3D and others) with the calendar of the construction work (initial schedule may fetch from Primavera, MS Project or other software systems), fill the calendar schedule with information from the estimates (using the integration of Grandsmeta or other similar programs).

In the classical scheme of organizing the procurement of the necessary materials for construction, the customer's service must keep a whole staff of specialists who will manually collect information about materials from the working documentation for the construction of the facility. This is a rather painstaking task that requires a lot of time. In modern realities, the implementation of this task becomes even more difficult, for which there are several reasons:

- the development of the Work Documentation is based on incomplete initial data, therefore, it becomes necessary to frequently adjust the documentation and the volumes included in it;

- the construction time is compressed, as a result of which it is necessary to early planning the procurement of materials in order not to disrupt the construction and commissioning of the facility;

- additional difficulties in planning resource provision during the construction of facilities in remote areas;

- a wide variety of use of effective materials, therefore, frequent and quick change of the laid down design solutions and materials.

To solve the above problems, it is proposed to use the Assistant Build information system with the use of BIM technologies. The information model of the object is loaded into the system, as a result of which information about each element of the model appears in the system - see Fig.1. 


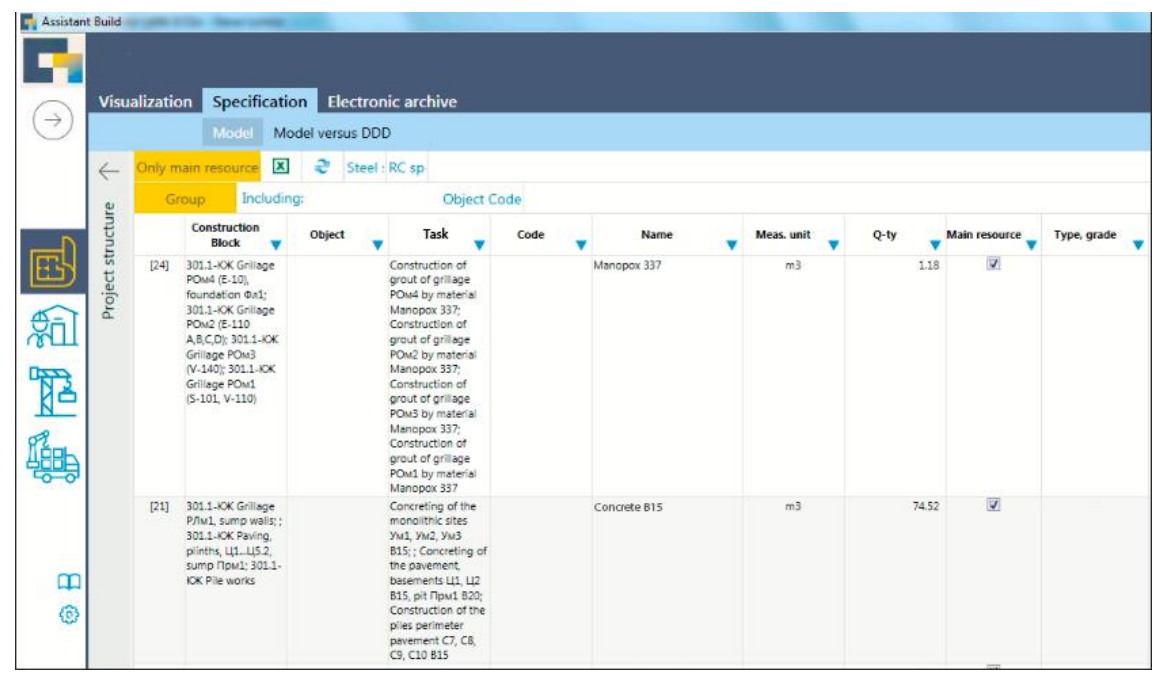

Fig. 1. BOM from BIM object model

The required amount of materials at any time, at the time of adjusting the model and design solutions, can be automatically obtained in the form of a summary specification for the logistics, which can be downloaded into a convenient and simple Excel table format see Fig.2.

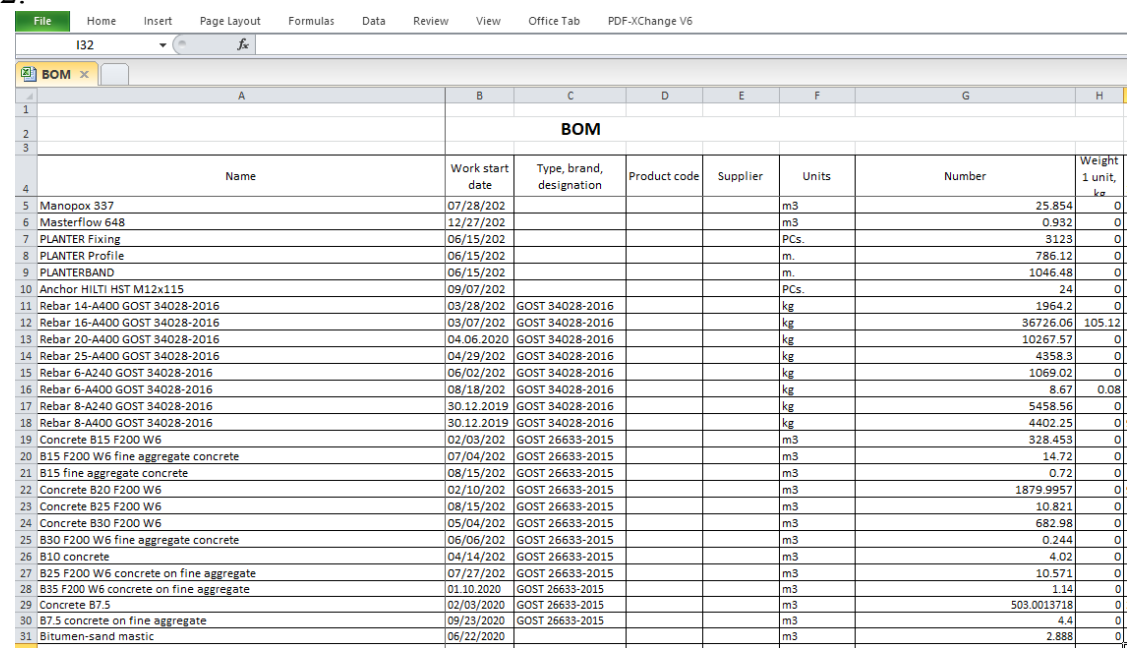

Fig.2. BOM for logistics obtained using the system Excel

The logistics module contains information about the number of purchased and delivered to the construction site groups of materials in a given period of time, which makes it possible to optimize the delivery schedule. The system has a powerful tool for shaping supply chains, tracking the shipment of materials, tracking the passage of checkpoints. As a result, it is possible to promptly adjust the schedule, taking into account the lag/advance of the supply of materials - see Fig.3. 


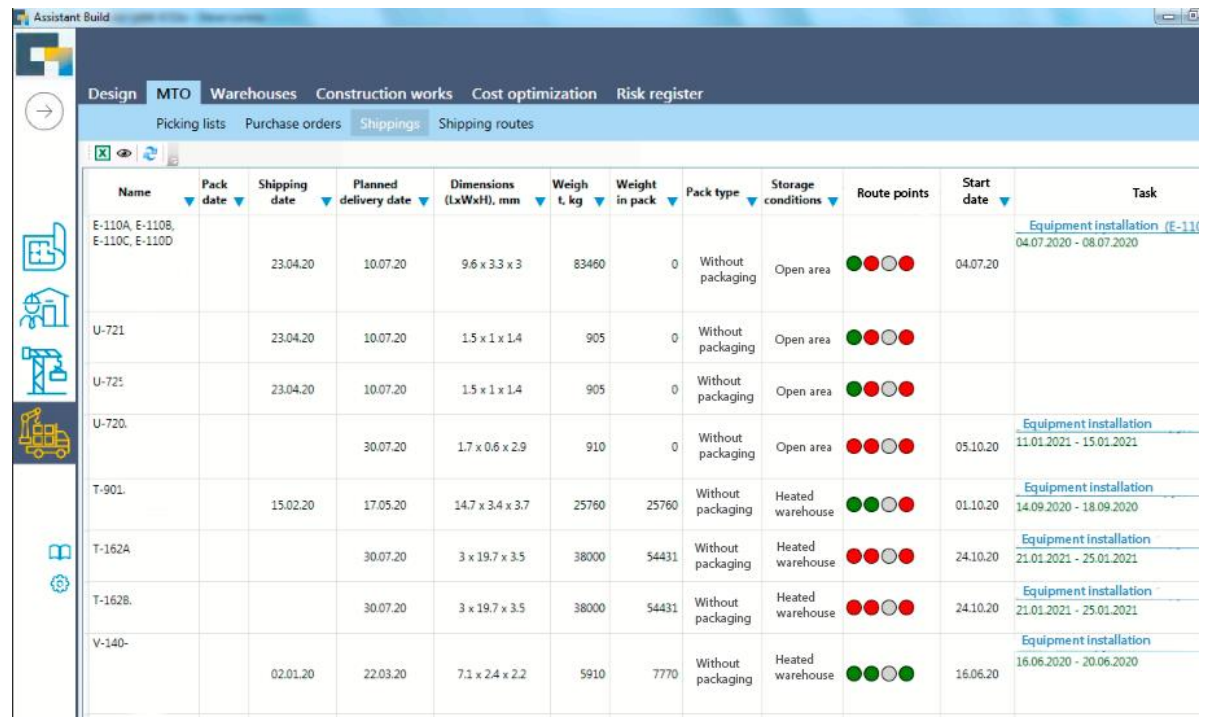

Fig.3. Monitoring shipment at control points in the supply chain

The main structural division of the construction object is the task to perform certain works. An assignment is a specific task to be performed on a construction site that is tied to specific objects in the object information model. It is the task that is the structural unit around which the construction management system is built. For example, Fig.4 shows a breakdown by assignments for the performance of piling works by objects.

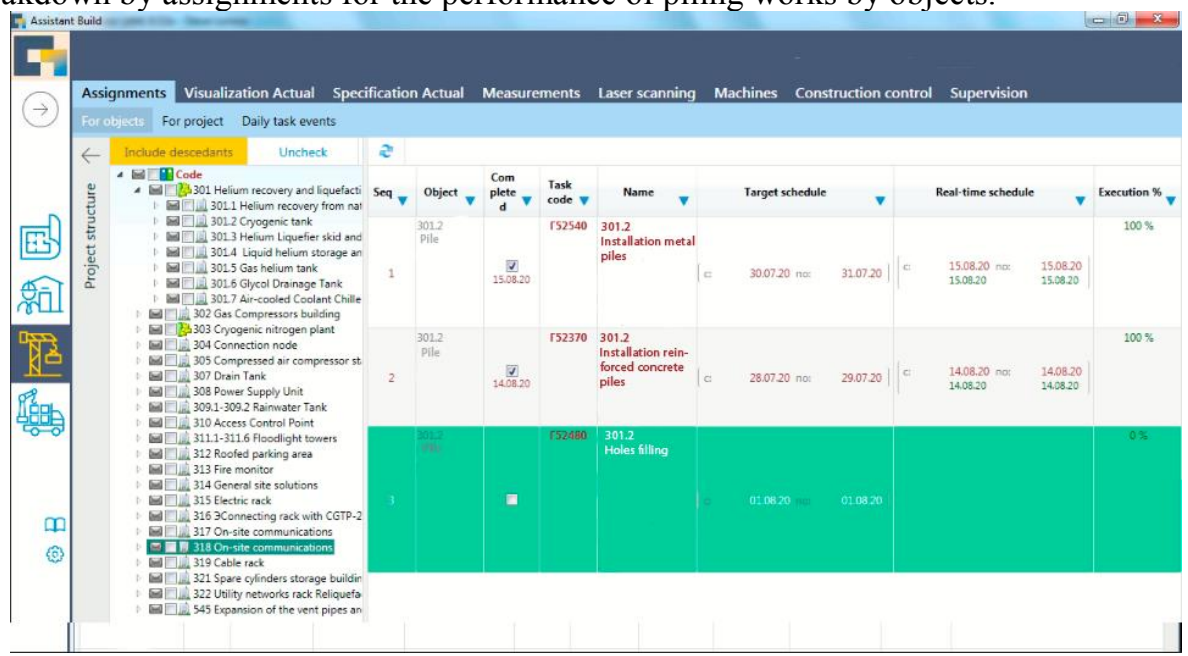

Fig.4. Construction tasks

The work schedule is drawn up in such a way that its structure coincides with the structure of tasks. At this stage, the position in the calendar schedule is linked with the target, i.e. with a specific element of the information model.

Each task is assigned a specific contractor who will perform this work. At the output, we have a calendar schedule, in which the work is connected with each other by a logical chain, which takes into account the order of work performed by contractors.

The major advantage of such a calendar schedule and that is associated with the job, which means with information events spruce is the ability to track the availability and 
actual production of required resources for construction. Figure 5 shows the planned BOM for the job, which is unloaded from the BIM model.

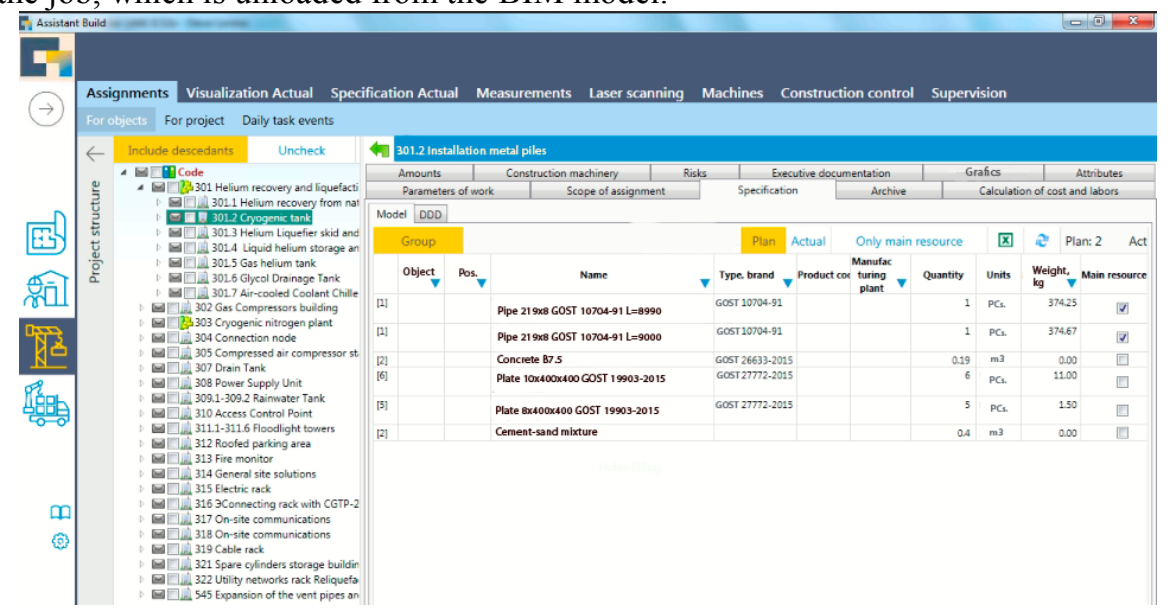

Fig.5. Planned BOM for the construction assignment

The card for each task from the estimated programs integrates information about the necessary labor costs to complete this or that task, the necessary additional materials, construction equipment and mechanisms. This information also falls into the general construction schedule.

The program is based on a set of tools for reporting on actual work performed as a 3D model of the object (see . Fig.6), and in the form of tables and diagrams to produce visual presentations of the report on the work

performed (see. Fig.7 and 8).

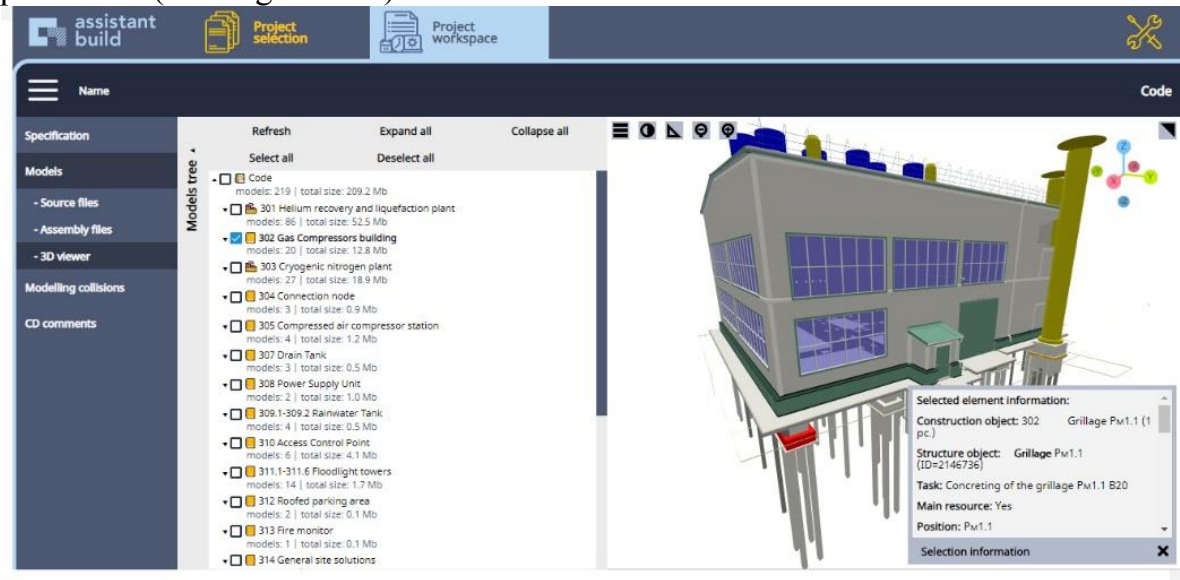

Fig.6. Actual 3D object model (built) 


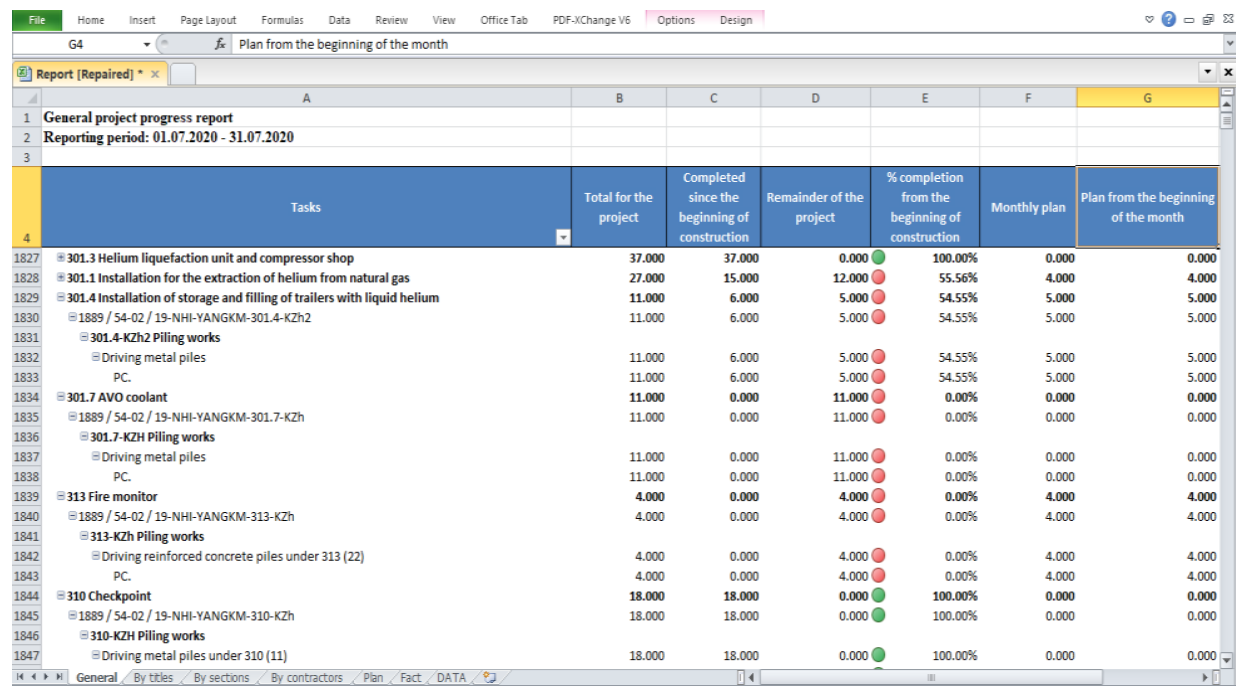

Fig.7. Report on the work performed and mastered materials in Excel table format

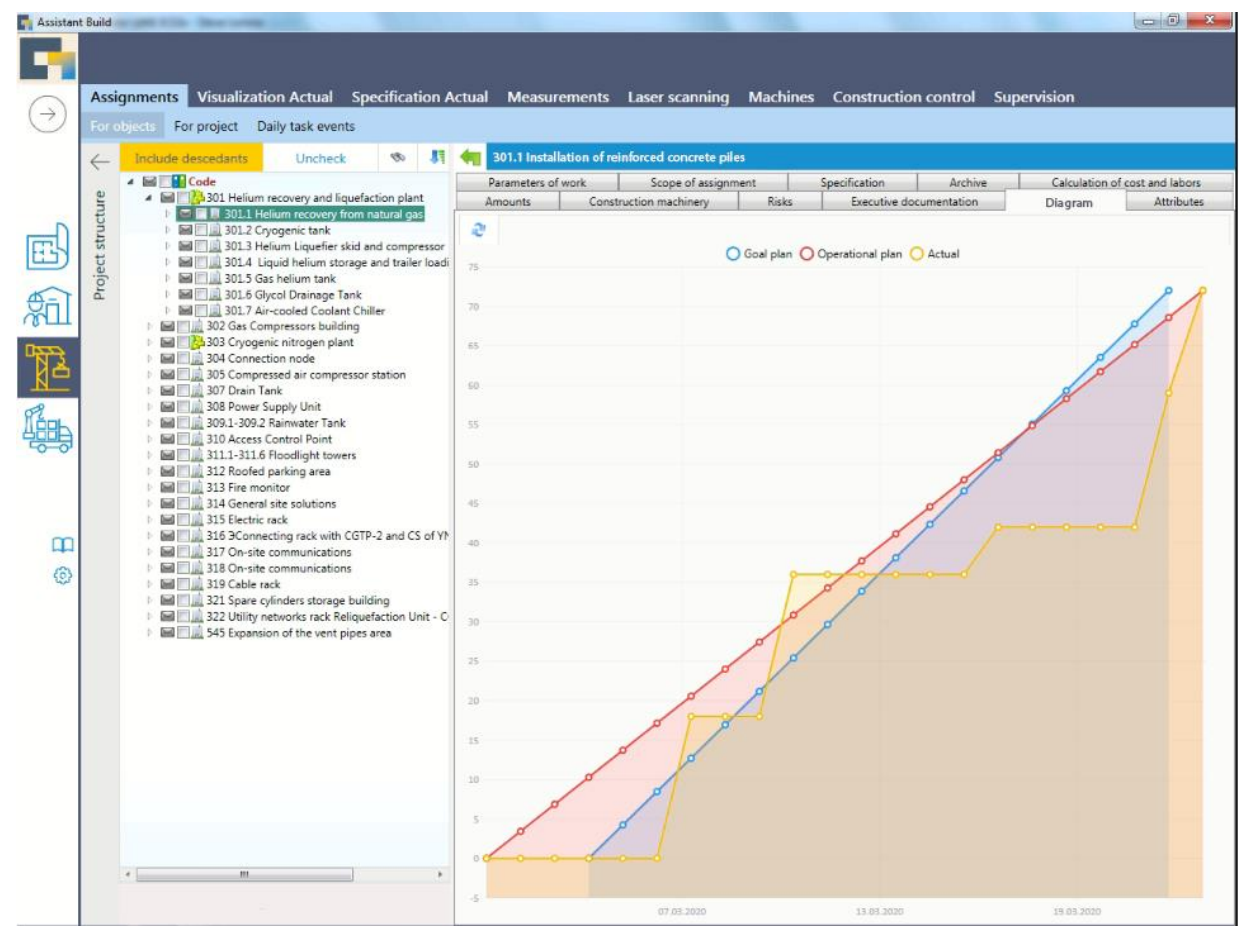

Fig.8. Schedule of planned and actually completed works

A very important advantage of the system is the ability to provide access via a smartphone in real time. To use all the functionality of the system, including: monitoring the progress of construction; control and tracking changes in specifications by section for timely adjustment of the purchase of missing materials; view of planned and actually sawed OPERATION 3D model; loading all the necessary files of the construction site workflow; you only need a smartphone and mobile internet. 


\section{Discussion}

The scientific value of the presented work lies in the fact that it presents a new, rapidly developing approach to planning and construction management using not only BIM technologies, but also the latest advances in the IT sector and digitalization of processes. It is clearly demonstrated that the classical principles of ensuring control over construction and providing the necessary resources and materials does not correspond to modern requirements and lags far behind modern technological and information capabilities. The importance of innovation in this area can hardly be overestimated, since efficient construction is the key to the rapid economic and technological development of the entire country.

\section{Conclusions}

As a result of research, it has been proven that with the use of complex computer systems, already in 2020 it is possible to effectively control construction, especially in matters of accurate, correct and timely provision of the construction site with the necessary materials. An important conclusion that was obtained as a result of the research is that the creation of a unified software system for the control system for construction production is a priority task in the field of organizing construction production. Simplicity, comfort of use even in the most remote areas of construction makes such systems indispensable and greatly facilitate construction management work.

\section{References}

1. A.V. Ginzburg Information model of the life cycle of a construction object, Industrial and civil construction 9, 61-65 (2016)

2. M.A. Gurieva, Prospects for the use of bim- design technology for the purpose of organizing the construction of real estate in mountainous conditions, Sustainable development of mountainous areas 5(2), 31-33 (2013)

3. M.A. Chegodaeva, The functionality of the information model at the stages of design, construction and operation of a building Young scientist 25(129), 102-105 (2016) https://moluch.ru/archive/129/35716/ (date accessed: 07/23/2020)

4. D.E. Ermolov, 4D modeling of construction in Russia and abroad Materials of the IX International Student Scientific Conference "Student Scientific Forum" https://scienceforum.ru/2017/article/2017031031 (date accessed: 23.07.2020).

5. N.M. Grishina, E.B. Zavodnova, 4D modeling technologies in construction SPbPU Science Week, Materials of a scientific conference with international participation, Civil Engineering Institute. At 3 o'clock. ed. N. D. Belyaev, V. V. Elistratov, 8-10 (2019)

6. A.M. Elsheikh, Automation of planning and formation of a 4D construction schedule, Scientific and technical bulletin of the Volga region 6, 374-376 (2014)

7. V.V. Sharmanov, T.L. Simankina, A.E. Mamaev, Control of construction risks based on BIM technologies https://readera.ru/143163572/ (date of access: 09/08/2020).

8. O. N. Kuzina, Formation of an information model "executive" at the construction stage (C-BIM), Science and business: ways of development 7 (97), 43-47 (2019) 
9. L.B. Zelentsov, L.D. Mayilyan, N.G. Akopyan, M.S. Shogenov,bModeling of organizational and technological processes in construction using modern digital technologies, Construction production, 1, 41-44 (2020).

10. N.P. Chetverik, The costs of BIM technologies in design are justified by their high efficiency http://zanostroy.ru/articles/1975/266.html\#x/(date of access: 08/08/2020).

11. BIM + work schedule (4D) http://genpro.ru/bim-grafik-rabot-4d (date of access: 08.08.20)

12. D.O. Lyalin, A.M. Yugov, Substantiation of rational technology for assembling a building with a metal frame using modern information technologies, Bulletin of the Donbass National Academy of Civil Engineering and Architecture 6(128) 46-52 (2017)

13. V.P. Grakhov, Yu.G. Kislyakova, U.F. Simakova, D.A. Mushakov, Development of a monitoring system for the progress of construction and installation works based on the integrated application of software products, Primavera P6 Professional R8.3.2 and Archicad 17.0.0 Science and technology 16(6) 466-474 (2017)

14. L.A. Manukhina, A.A. Yashchenko, Integration of organizational and technological solutions in BIM, Innovative technologies in science and education 2(2), 246-249 (2015)

15. M.V. Danilov, P.A. Dedyukhova, D.V. Napolskikh, Logistics in the management of material resources of the project in construction, Socio-economic management: theory and practice 3(34), 121-125 (2018)

16. R.B. Garibov, A.V. Pakhomova, R.R. Bashirzade, Logistics of construction projects, Bulletin of the Rostov State Economic University (RINH) 2(54), 22-29 (2016)

17. D.Yu. Tsaregorodtsev, The state of logistics in the construction industry: problems and directions of development, Russian regions in the focus of change: collection of articles. rep. XI Int. conf., 462-470 (2016)

18. S.M. Vaisman, A.Kh. Bayburin, Development of organizational and technological solutions in construction using information modeling technologies (TIM), Bulletin of SUSU. Series: Building and architecture 4, (2016) https://cyberleninka.ru/article/n/razrabotka-organizatsionno-tehnologicheskih-resheniyv-stroitelstve-s-ispolzovaniem-tehnologiy-informatsionnogo-modelirovaniya-tim (date of access: 08/09/2020).

19. BIM in the budget business - the current situation and prospects https://ipap.ru/poleznye-stati/4-useful/bim-v-smetnom-dele-tekushchaya-situatsiya-iperspektivy/ (date accessed: 09/08/20)

20. M.G. King, BIM: information modeling - the digital age of the construction industry, Stroymetall, 26-30 (2014)

21. 5D Building Information Modeling https://infars.ru/bim/5d/ (date of access: 08/09/20)

22. D.V. Topchiy, A.Ya. Tokarskiy, Improvement of the construction and installation work management process through the use of information models in the implementation of supervisory procedures, Construction production 2, 30-35 (2019)

23. A.E. Mamaev, V.V. Sharmanov, Yu.S. Zolotova, V.A. Svintsitsky, G.S. Gorodnyuk, Application of the BIM-model of a building to control an investment and construction project, Actual problems of the humanities and natural sciences 1(3), 83-87 (2016)

24. A.E. Mamaev, Methods for monitoring the construction schedule based on BIM technology, Fundamental research 8-2, 270-275 (2017) 